\title{
A virus view of the human condition
}

I am a harmless human virus, one of the 65 or so different ones that cause warts. Although a few of my genital colleagues may cause you more serious trouble (cancer), I am well adjusted to my humble life on knuckles and knees. I know my place. And as one of your most ancient and successful viruses, directly descended from those that made warts on your simian ancestors a few million years ago, I feel that I am in a good position to speak on behalf of all the other viruses, not all of whom have been so undemanding, and I hope that what I have to say will reach the ears of the hundreds of viruses that infect non-human animals and arthropods. These are the ones that are often tempted into irresponsible behaviour in our human friends.

I say human friends because it is clear to us, as evolutionary survivors, that it will not be too long before the human body is the only refuge for an animal virus. Doubtless you will always keep a few domestic animals, but as your billions occupy every corner of the planet and monopolize the food supplies, most animal species are doomed to extinction or to a token life in zoos. I mention this because extinction of any species means also extinction for a group of my relatives. Indeed, when I look at the human condition in this way, the best, long-term strategy for a virus living at present in some other species would be to switch to the human host. But they should be careful about it, as I'll explain.

I said earlier that I am well adjusted to my human habitat. But it has not been easy. You have those formidable local defences to stop us sticking onto you or getting into you, and if we do manage to gain entrance you have that much more powerful weapon of adaptive immunity ready for use against us, which usually stops our activities, kills us off, and clears us out. ${ }^{1}$ So, like all other microbes and parasites, we have had to devise ways round those defences. Otherwise we would not have survived. Every defence, every immune weapon, has provoked a response. We have learnt how to avoid those terrifying phagocytes, how to dodge the deadly aim of antibodies and T cells. I hear that your scientists and students are having problems understanding the way in which the great army of cytokines cooperates with the immunoglobulins, $T$ cells, and macrophages. For us it has been a matter of life and death to be clear about this. We have been forced to become brilliant cell biologists, much more familiar with life in the cell than your cleverest scientists. For example, we have been interfering with your immune signalling system for thousands of years by manufacturing decoy molecules to mimic the cytokines or the cytokine receptors on cell surfaces. ${ }^{2}$ Another example is the ingenuity with which so many of us have avoided your interferon weapon, either stopping it being formed or escaping its powerful action. Death has been the penalty for a strategy that did not work. It has always been a good strategy to interfere with the immune system. Measles and many other viruses have found this useful. But it has to be a subtle, temporary interference, if we are not to inflict serious damage on our host. HIV has taken the strategy of immunosuppression to such ridiculous lengths that nearly all infected people are killed in the end by other normally quite harmless microbes. It is just what you might expect from a recently arrived, unadapted human pathogen!
Some of us, including my own family of papillomaviruses, were quite literally not in a position to interfere with the immune system. We chose the simple solution, and kept out of its way. The skin is a fortress, immunologically speaking, so we maintain ourselves by colonizing the basal layer of cells, where we keep a low profile, releasing no proteins to betray our presence. We do not begin to multiply and produce infectious offspring until the cells are safely on their journey to the body surface, well-removed from antibodies and wandering $T$ cells. It has paid off, and that's one reason why there are so many of us, in many different animals, adapted to different parts of the body.

At present I'd say that most of us enjoy moderately good relations with humans and maintain ourselves in your populations without doing too much damage. The fact that some of us cause serious illness in hospital patients is an unfortunate result of your skill in keeping alive people whose defences are crippled. Diseases like glandular fever or congenital rubella only occur when we are prevented from infecting you all in childhood. EB virus is as harmless as cytomegalovirus when it infects small children. If you start complaining about the children who die from measles I can only apologise and say that this is a fairly recent human infection and is still settling down in your species after its jump across from cattle (rinderpest) a few thousand years ago.

Before the birth of your towns and cities, when you lived in small scattered groups, things were much harder for us. Once we had infected all the people in a group and they had recovered, there was nowhere else for us to go and we died out locally. But our ancestors long ago mastered the art of staying on in your bodies. To do this we had to lie low, in a state of suspended animation. Yet there was no point in doing this unless at some later stage we could spread to fresh hosts, so we invented reactivation. It was difficult to master the technique, but it meant that after an interval of many years we could start growing again, leave the body, and infect the new group of young people that had by then appeared in the community. The signals for reactivation generally had to be naturally occuring events like pregnancy (polyomaviruses) or getting old (zoster). It enabled us to stay as parasites in those isolated groups of people. ${ }^{3}$ But today in your crowded communities this is no longer necessary, and whether we spread by droplets or by sex there are always plenty of susceptible hosts.

Which brings me to my main worry. Unfortunately there will always be a few irresponsible viruses that spread well but cause excessive damage. What happens then is that either you are so reduced in numbers that we have difficulty finding you, or we have a hard time in the survivors because they have developed genetic resistance. You will recall this sequence of events with tuberculosis in 19th-20th century Europe, and more recently with our distant relative myxoma virus in Australian rabbits. ${ }^{4}$ The irresponsible viruses are always there, in non-human animals or in biting insects, and have frequent opportunities to develop mutant strains that will infect you. I don't have to remind you about the life-threatening disease caused by Marburg, Ebola, Lassa and the hantaviruses, or the recent measles-like virus in Queensland, Australia, that killed horses and humans. ${ }^{5}$ On 
the other hand, these infections pose no great threat to most of you as they are geographically localised, episodic, and fail to spread from person to person. What is of real concern to us is that one of them could develop a mutant strain that spread efficiently in your species. If the mutant virus spread by the fecal-oral or the sexual route it would not matter much because you can prevent or reduce this sort of spread - even HIV is not going to kill off more than a few per cent of you as long as it only spreads by blood and sexual activity. But droplet spread is another matter. I have only to talk to my rhinovirus or influenza virus aquaintances to know what a problem you already have with respiratory infections. Your crowded species is uniquely vulnerable to this sort of spread. ${ }^{6}$ What a catastrophe if Ebola or HIV virus foolishly learnt the trick of respiratory transmission and upset life for all us well behaved viruses.

I've talked about new viruses from animals and arthropods, but you should also keep an eye on the droplet-borne viruses. It would be disastrous for us if one of the bird influenza viruses joined up again with a human one and produced a new and really lethal influenza $A$ pandemic. ${ }^{7}$ I'm afraid that some viruses would be prepared to kill off most of you for their short-term benefit, showing no consideration for the rest of us, and we certainly cannot be held responsible. One sometimes has to do a certain amount of damage just to be transmitted (eg, diarrhoea, colds in the nose or urethra), but causing serious damage is quite unjustified.

So far we have for the most part been spared the serious challenge that you posed to the bacteria when you discovered antibiotics. There are not many antivirals that we worry about just now, although we are aware that more effective ones will come before long. On the other hand, viral vaccines have dealt us some severe blows, whereas most of the bacteria so far have been fortunate. In 1796, when the English physician Edward Jenner vaccinated eight-yearold James Phipps with cowpox virus and protected him from smallpox, our ancestors were alarmed but not seriously worried. After all, it was simply a matter of one virus getting there first and preventing infection by a close relative. This happens all the time among antigenically related viruses. But they were forgetting that cowpox, even if it were a bona fide virus, did not spread among humans and therefore had no future in them. Certainly we never dreamt that one day a handful of committed, far-sighted humans, on a total budget (\$US 150 million) no greater than the cost of one or two of your nuclear weapons, would organise the total elimination of smallpox. ${ }^{8}$ Viruses are always becoming extinct, and we accept this evolutionary fact, but this unprecedented human achievement came as a severe shock. We now keep an anxious eye on other threatened viruses, and are alarmed that there have been no cases of poliomyelitis in the Americas for seven years, and that measles will soon be eliminated from developed countries. The formation of international alliances like the CVI (Childrens Vaccine Initiative) and the probable development of multiple, one dose vaccine 'cocktails' for children, are ominous signs. But you are surely not going to waste time and money on those of us that are relatively harmless! I feel confident that as far as viruses are concerned the meek will inherit the earth.

You had a great writer who, had he been alive today, would certainly have had something to say about viruses. Even so, 500 years ago, he described herpes simplex when he referred to 'ladies lips ... which oft the angry Mab with blisters plagues' (Romeo and fuliet). I mention him because another of his characters noted that 'there are more things in heaven and earth, Horatio, than are dreamt of in your philosophy' (Hamlet), and I want you to take that message on board. Never underestimate us, or imagine that you have had the last word. Our future depends on being transmitted, and I must remind you that in the modern world new strategies are open to us. I'll suggest two that are benign. Supposing one of us, transmitted by the sexual route, made a peptide in your body that greatly stimulated the sexual appetite without making you sick. That would be a fine arrangement from our point of view. Or supposing one of our herpes virus colleagues transmitted by kissing made a molecule that caused intense euphoria, like heroin but without heroin's problems. Surely all of you would then strive to become infected.

Looking far ahead, I foresee the day when you have cleaned up the human body, got rid of the ancient infections that were all very well in the past ${ }^{9}$ but which are intolerable in a modern, less contaminated world. Perhaps as a long term strategy we should try and do something actually useful for you in exchange for board and lodging, become welcome guests rather than old-fashioned parasites. And to be willingly transmitted by humans would be just the sort of boost that we, the parasites, need most at this stage in evolution, because you are the dominant species. We are well aware that most of our old methods of transmission, such as by way of the intestinal tract or biting arthropods are going to become impossible or unprofitable in the 21 st century.

I will end by letting you know that our greatest enemies, as always, are the men in the laboratories. Luckily most of them are busily pursuing popular fads rather than using their imaginations or entertaining thoughts that could be dangerous for us!

CA MIMS Sheriff House, Hammingden Lane, Ardingly, Sussex RH17 6SR, UK

1 Mims CA, Playfair JHL, Roitt IM, Wakelin D, Williams R. Medical microbiology. London: Mosby, 1993.

Smith GA. Virus strategies for evasion of the host response to infection. Trends Microbiol 1994; 2: 81-8.

3 Black FL, Herholzer WJ de P, Pinheiro F, et al. Evidence for persistence of infectious agents in isolated human populations. Am 7 Epidemiol 1974; 100 230-54.

4 Fenner F. Myxomatosis in Australian wild rabbits - evolutionary changes in

5 Murray K, Selleck P, Hooper P, et al. A morbillivirus that caused fatal disease in horses and humans. Science 1995; 268: 94-7.

6 Mims CA. Virology research and virulent human pandemics. Epidemiol Infect 1996; (in press)

7 Webster RG, Bean WJ, Gorman OT, et al. Evolution and ecology of Webster RG, Bean WJ, Gorman OT, et al. Evolu
influenza viruses. Microbiol Rev 1992; 56: 152-79.

8 Fenner F. A successful eradication campaign. Global elimination of smallpox. Rev Infect Dis 1982; 4: 916.

9 McNeil WH. Plagues and peoples Oxford: Blackwell, 1977. 